\title{
IL-36 cytokines in inflammatory and malignant diseases: not the new kid on the block anymore
}

\author{
James Byrne ${ }^{1} \cdot$ Kevin Baker $^{1} \cdot$ Aileen Houston $^{2,3} \cdot$ Elizabeth Brint $^{1,3}$ (D)
}

Received: 10 June 2021 / Revised: 27 July 2021 / Accepted: 29 July 2021 / Published online: 7 August 2021

(c) The Author(s) 2021

\begin{abstract}
The IL-36 family of cytokines were first identified in 2000 based on their sequence homology to IL-1 cytokines. Over subsequent years, the ability of these cytokines to either agonise or antagonise an IL-1R homologue, now known as the IL-36 Receptor (IL-36R), was identified and these cytokines went through several cycles of renaming with the current nomenclature being proposed in 2010. Despite being identified over 20 years ago, it is only during the last decade that the function of these cytokines in health and disease has really begun to be appreciated, with both homeostatic functions in wound healing and response to infection, as well as pathological functions now ascribed. In the disease context, over activation of IL-36 has now been associated with many inflammatory diseases including Psoriasis and inflammatory bowel diseases, with roles in cancer also now being investigated. This review summarises the current knowledge of IL-36 biology, its role in inflammatory diseases and focuses on an emerging role for IL-36 in cancer.
\end{abstract}

Keywords Interleukin-36 $\cdot$ IL-1 family $\cdot$ Cytokine $\cdot$ Inflammation $\cdot$ Disease $\cdot$ Cancer

\section{Introduction}

The IL-36 family of cytokines was first identified in 2000 based on their sequence homology to IL-1 cytokines [1]. Over subsequent years, the ability of these cytokines to either agonise or antagonise an IL-1R homologue, now known as the IL-36 receptor (IL-36R), was identified and these cytokines went through several cycles of renaming with the current nomenclature being proposed in 2010 [2]. Despite being identified over 20 years ago, it is only during the last decade that the function of these cytokines in health and disease has really begun to be appreciated, with both homeostatic functions in wound healing and response to infection, as well as pathological functions now ascribed. In the disease context, over activation of IL-36 has now been

\section{Elizabeth Brint}

e.brint@ucc.ie

1 Department of Pathology, Cork University Hospital, University College Cork, Clinical Sciences Building, Cork, Ireland

2 Department of Medicine, University College Cork, Cork, Ireland

3 APC Microbiome Ireland, University College Cork, Cork, Ireland associated with many inflammatory diseases including Psoriasis and inflammatory bowel diseases, with roles in cancer also now being investigated. This review summarises the current knowledge of IL-36 biology, its role in inflammatory diseases and focuses on an emerging role for IL-36 in cancer.

\section{IL-36 cytokines}

The IL-36 family of cytokines and its cognate receptors are a subfamily belonging to the IL-1 superfamily, with 3 agonistic-IL-36 $\alpha$, IL-36 $\beta$ and IL-36 $\gamma$ members, as well as the IL-36 Receptor antagonist (IL-36Ra) and IL-38 that function to antagonise these pro-inflammatory cytokines. These were previously termed IL-1F6, IL-1F7, IL-1F8, IL-1F5 and IL-1F10, respectively, and share common functionalities with the IL-1 family members [3]. Various genetic recombination and sequencing experiments have shown that IL-36 encoding genes are positioned on chromosome $2 q 13$ within a $450 \mathrm{~kb}$ IL-1 gene cluster and are classified as IL-1 homologs based on bioinformatics and functional analyses. These cytokines are widely expressed by keratinocytes, endothelial cells, brain tissue and various immune cells [4, 5]. Further studies examining the regulation and cellular expression of IL-36 cytokines have shown a certain level of divergent regulation of the three agonistic cytokines. For 
example, keratinocytes constitutively express IL-36 $\alpha$ but can induce IL-36 $\gamma$ upon TNF $\alpha$ stimulation; whereas, the

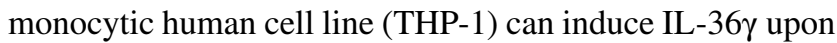
TLR2/4 agonist stimulation [6, 7].

IL-36 $\alpha, \beta, \gamma$ and the IL-36Ra are synthesised as inactive progenitors and undergo proteolytic cleavage to become completely activated. IL-36 cytokines lack both caspase-1 cleavage sites and signalling peptide sequences. The absence of a signalling peptide sequence illustrates that IL-36 cytokines have an alternative secretory pathway independent of the endoplasmic reticulum. The secretory pathway of IL-36 cytokines was originally studied in bone-marrowderived macrophages (BMDMs) engineered to overexpress IL-36 $\alpha$ and demonstrated that IL-36 $\alpha$ secretion is rapidly induced by LPS/ATP-mediated activation of the P2X7 receptor. This indicates that IL-36 $\alpha$ secretion is stimulus dependent compared to IL- $1 \beta$ which requires inflammasome activation [8]. To realise optimal biological function, IL-36 cytokines require proteolytic cleavage and enzymatic activity. Proteases secreted from neutrophils or lymphocytes, such as Cathepsin G, Elastase and Proteinase-3, can enhance the biological activity of the IL-36 cytokines. Neutrophils can release Net-bound proteases to cleave the pro-isoforms of IL-36 to its activated form. These proteases cleave specifically at truncated sites with AXN motifs located at the $\mathrm{N}$-terminus. These post-translational modifications result in a 10,000-fold increase in activity. The antagonistic function of IL-36Ra require its cleavage at a methionine residue situated at the N-terminus. For IL-36 $\alpha$ activation, both Cathepsin $\mathrm{G}$ and Elastase are necessary for Lys3 and Ala4 cleavage, whereas Cathepsin G cleaves IL-36 $\beta$ at residue Arg5. In contrast, Cathepsin S secreted by endothelial cells can cleave IL-36 $\gamma$ between Glut17 and Ser18 residues [3, 9].

\section{IL-36 signalling}

Similar to other cytokine members of the IL-1 family, IL-36 agonists (IL-36 $\alpha, \beta, \gamma$ ) engage a heterodimeric receptor comprising of the IL-36R (previously termed IL-1Rrp2) and the IL-1R accessory protein (IL-1RAcP) [2]. IL-36R is expressed by many different cell types, including keratinocytes, lung fibroblasts and epithelial cells in direct contact with the environment, endothelial cells as well as by various immune cells. IL-36R is also highly expressed in human M0 and M2 macrophages, but not in M1 macrophages [10]. Structurally, the IL-36R resembles the other activatory IL-1 receptor family members containing three conserved extracellular immunoglobulin domains, a transmembrane domain and an intracellular Toll/IL-1 receptor (TIR) domain [11]. IL-36R signalling is mediated by IL-36 agonists competitively binding to the IL-36R. IL-36R activation promotes IL$1 \mathrm{RAcP}$ recruitment which is classified as an active signalling component of the IL-36R receptor complex. Crystallisation studies of the IL-36R have shown residues Asp150, Asn148 and Ala162 are necessary for hydrogen bonding formation and IL-36 $\alpha, \beta, \gamma$ binding, respectively [12]. Following IL36R:IL-1RAcP heterodimerisation, TIR-induced signalling events are mediated through the homodimerisation and phosphorylation of the two TIR domains, with subsequent signalling events shown to be MyD88 dependent [13].

Analogous to all family members, IL-36 signalling induces inflammatory responses pathway occurs through the classical MyD88-IRAK-TRAF-TAK-TAB pathway $[14,15]$ resulting in activation of MAP kinases and $\mathrm{NF}-\mathrm{KB}$ pathways and triggering classical pro-inflammatory cytokine expression. Ultimately, IL-36 signalling activates downstream effector proteins to trigger the transcription of pro-inflammatory genes (Fig. 1). A comprehensive analysis and comparison of genes activated by IL- $1 \beta$ and IL-36 has been performed in keratinocytes using RNA-seq. Some early IL- $1 \beta$ specific responses were identified but nearly all late IL-1 $\beta$ responses were replicated by IL-36. Interestingly,

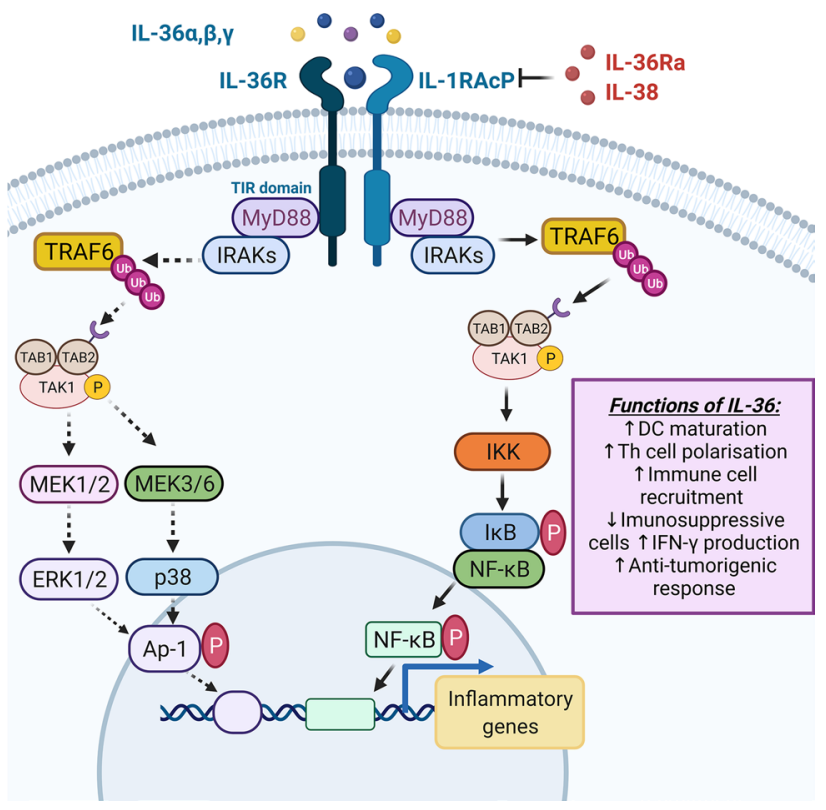

Fig. 1 IL-36R signalling: IL-36 agonists bind to the IL-36R, with activation promoting the formation of the IL-36R:IL-1RAcP complexes. IL-36Ra and IL-38 prevents IL-36R signalling by inhibiting IL-36:IL-1RAcP heterodimerisation. IL-36R:IL-1RAcP complexes induce TIR activation and MyD88 recruitment. The IL-36 signalling pathway occurs through the classical MyD88-IRAK-TRAF-TAKTAB pathway. Phosphorylated TAK1 promotes MAPK and NF- $\mathrm{BB}$ signalling by inducing MAPK kinase and IKK activation. IKK phosphorylates I $\mathrm{B}$, thus releasing NF- $\kappa \mathrm{B}$ while the MAPK kinase activates $\mathrm{p} 38 \mathrm{MAPK}, \mathrm{ERK} 1 / 2$, and AP-1 proteins. NF- $\mathrm{KB}$ and AP-1 proteins undergo nuclear translocation and promote the transcription of inflammatory genes. IL-36 signalling promotes DC maturation, Th cell polarisation and anti-tumorigenic responses. Image created with BioRender.com 
between the three IL-36 cytokines, 70-90\% of genes regulated by one IL-36 cytokine were correspondingly altered by another at the same time point. Many of these were similarly altered by IL-1B, and it was possible to identify genes with consistent responses to all four cytokines [13]. These findings indicate a high level of redundancy between IL-36 cytokines in terms of genes activated in keratinocytes, although it remains to be identified whether this same pattern will be true across other cell types.

\section{Regulation of IL-36 signalling}

IL-36Ra and IL-38 have been shown to negatively regulate the IL-36 signalling pathway. IL-36Ra was the initial IL-36 cytokine discovered and it shares $44 \%$ sequence homology with IL-1Ra [16]. IL-36Ra exhibits antagonistic function by competitively binding to IL-36R, suppressing IL-36 agonist recognition and IL-1RAcP recruitment, thus inhibiting activation of the receptor by the agonistic members of this family [5]. In addition to blocking IL-36R-mediatied activation of MAP kinases and NF- $\kappa B$ pathways, IL-36Ra can also prevent the expression of $\mathrm{Th}_{17}$ cytokines if exposed to Candida albicans or Aspergillus species [17]. Unlike IL-1RA, which is purely inhibitory, the IL-36RA can itself induce the expression of cytokines in glial cells, with IL-36Ra shown to induce upregulation of IL-4 mRNA/protein expression through IL-1 orphan receptor SIGIRR/TIR8 recruitment in vitro [18].

IL-38 shares similar characteristics with IL-36Ra. In vitro

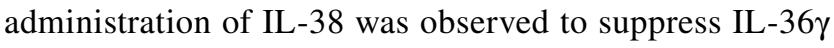
biological activity in human peripheral blood mononuclear cells [17]. Using murine models, IL-38 has been shown to ameliorate skin inflammation in an imiquimod-induced psoriasis model [19]. IL-38 also demonstrates anti-inflammatory properties by preventing the upregulation of $\mathrm{Th}_{17}$ cytokines [20]. Thus, IL-38 could function as a potential therapeutic tool in numerous inflammatory diseases.

\section{Physiological functions of IL-36}

The physiology functions of IL-36 have been well characterised in multiple cell types. Much data are now available indicating that these pro-inflammatory cytokines play key roles both in homeostatic functions and protection against infection.

\section{Homeostatic functions of IL-36}

Studies have elucidated that IL-36 cytokines play a significant role in maintaining tissue homeostasis in the skin and intestine $[21,22]$. In the skin, IL-36 cytokines are normally expressed at relatively low levels. During tissue damage, however, RNAs from damaged cells activate toll-like receptor 3 (TLR3), which increases the production of IL-36 $\gamma$. IL-36 $\gamma$ in turn initiates the wound healing response by inducing keratinocyte proliferation, differentiation and re-epithelialisation through enhanced REG3A expression. Induction of IL-36 following Toll-like receptor-3 (TLR3) also requires the induction of SLUG, which suppresses expression of the vitamin D receptor (VDR), thus abrogating the inhibitory effect of VDR on the IL-36 $\gamma$ promoter [23, 24]. Epidermal growth factor (EGF) signalling has also been shown to induce the expression of IL-36 $\alpha$ and IL-36 $\beta$ in damaged keratinocytes. Murine models deficient in a disintegrin and metalloproteinase-17 (ADAM-17), which is a membraneanchored metalloproteinase that is a crucial upstream regulator of EGFR signalling exhibit defective epithelial barrier function, elevated IL-36 $\alpha$ and IL-3 $\beta$ levels and enhanced keratinocyte proliferation [25]. Similarly, Yang et al. showed that a deficiency of fibroblast growth factor receptor (FGFR) signalling in the skin results in defective epithelial barrier function, enhanced keratinocyte and $\gamma \delta \mathrm{T}$-cell activation and elevated IL-36 $\beta$ expression [26]. Together, these studies highlight a role for IL-36 in promoting keratinocyte proliferation and maintaining skin homeostasis.

Several studies have demonstrated that IL-36 cytokines also play an important role in maintaining intestinal tissue homeostasis and in promoting intestinal wound healing. In intestinal lesions, IL-36 $\gamma$ is localised in the nuclei of intestinal epithelial cells and IL-36 $\alpha$ in $\mathrm{CD}_{14}{ }^{+}$inflammatory macrophages. During intestinal tissue damage, IL-36 $\gamma$ is released and promotes mechanical wound healing by inducing nucleophilic infiltration and proliferation of IL-36R ${ }^{+}$ colonic fibroblasts [22]. Similarly, Kanda et al. revealed that IL-36 $\alpha / \gamma$ promote the proliferation of colonic subepithelial myofibroblast through enhanced phosphorylation of ERK1/2, p38 and IKB $\alpha$ [27]. Moreover, IL-36R ${ }^{-/-}$mice display reduced neutrophilic recruitment and impaired wound closure of colonic mucosal biopsy upon dextran sodium sulphate Sodium (DSS)-induced damage [28]. A cytokine network involving IL-23, IL-22 and IL-36 has been described to be important in intestinal wound healing. IL-36R-deficient and IL-36 $\gamma$-deficient mice exhibited dramatically reduced IL-23, IL-22, and antimicrobial peptide levels, and consequently failed to recover from acute intestinal damage [29]. In conclusion, the IL-36R signalling pathway functions in maintaining intestinal homeostasis and dysregulation of this pathway can contribute to inflammatory pathologies.

\section{II-36 cytokines as regulators of the inflammatory response}

Similar to other IL-1 cytokine family members, IL-36 plays significant role in immunity by stimulating both innate and 
adaptive immune responses. The IL-36R has been shown to be highly expressed in dendritic cells (DCs), and activation by IL-36 promotes DC maturation and antigen presentation by downregulating $\mathrm{CD}_{1} \mathrm{a}^{+}$and up-regulating HLA-DR, CD83 and CD86 proteins, as well as the secretion of various inflammatory cytokines, including IL-12 [30]. IL-36R is also expressed by monocytes and is highly expressed in human M0 and M2 macrophages, but not in M1 macrophages, with IL-36 stimulation increasing production of inflammatory cytokines by these M2 macrophages [10]. However, conflicting results have been reported on the role of IL-36 on human T-cell function. Some studies have reported that $\mathrm{T}$ cells do not express the IL-36R and do not directly respond to IL-36 stimulation [31] [10]. In contrast, human blood and intestinal $\mathrm{T}$ cells $\left(\mathrm{CD} 4^{+}\right.$and $\left.\mathrm{CD} 8^{+}\right)$, as well as B cells were shown to express the IL-36R, with IL-36 $\beta$ inducing both the upregulation in expression of the receptor and the rapid proliferation of $\mathrm{CD}^{+} \mathrm{T}$ cells [32]. IL-36 has also been shown to potently induce T-cell polarisation and IFN- $\gamma$ expression [4]. IL-36 cytokines induced the proliferation of naïve $\mathrm{CD} 4^{+} \mathrm{T}$ cells and IL- 2 production, and acted in synergy with DC-derived IL-12 to induce the polarisation of naïve $\mathrm{T}$ cells into IFN $\gamma$-producing Th1 cells. Activation of the IL-36R in $\mathrm{CD} 4^{+} \mathrm{T}$ cells can also inhibit their differentiation into regulatory $\mathrm{T}$ cells and instead redirect them toward IL-9-producing T effector cells (Th9) via a pathway involving MyD88 and NFkBp50 [33]. Th9 cells are a recently described subgroup of $\mathrm{CD} 4^{+} \mathrm{T}$ cells that play an important role in various immune-related diseases, including inflammatory diseases, auto-immune disease and tumours [34]. Together, these findings suggest that activation of the IL-36R on immune or epithelial cells may act as an early danger signal to activate cells of the innate and adaptive immunity such as DCs and naive $\mathrm{CD} 4^{+} \mathrm{T}$ cells to stimulate host responses against pathogens (Fig. 2).

\section{IL-36 as key cytokines in host response to infection}

The importance of IL-36 as a regulator of inflammatory responses has been borne out by evidence indicating its role in microbial, bacterial and viral infections. Activation of the IL-36R on skin keratinocytes resulted in the upregulation in the expression of the type I interferon (IFN) receptor complex by the cells, increasing cellular sensitivity to IFN, thus supporting immune responses against viruses that inhibit innate immunity by blocking production of type I IFN [35]. Consistent with this an anti-viral function, IL-36 $\gamma$ protects against severe influenza infection by limiting viral replication and prevent the death of alveolar macrophages in influenza-infected mice [36]. IL-36 $\gamma$ was also shown to protect against HSV-2-mediated genital disease using HSV-2-infected mice. Pre-treatment with IL-36 $\gamma$ promoted the expression of immune mediators and immune cell

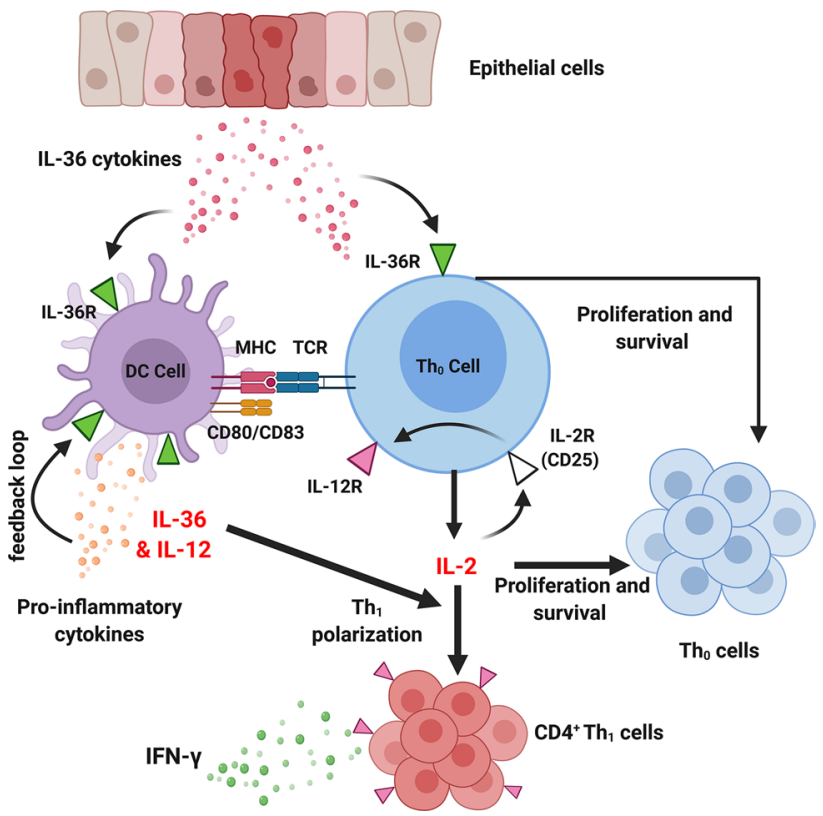

Fig. 2 The role of IL-36 on dendritic cells (DCs) and $\mathrm{CD}^{+}$naïve T cells: IL-36 promotes DC maturation and antigen presentation by up-regulating MHC class II molecules and CD80/83 proteins. Upon tissue injury, IL-36 cytokines are released, activating the IL-36R expressed by DCs. IL-36// $\gamma$ binding upregulates production of IL-12 which promotes the differentiation of naïve $\mathrm{T}$ cells $\left(\mathrm{Th}_{0}\right)$ into $\mathrm{Th} 1$ cells. In addition, IL-36R signalling induces naïve T-cell $\left(\mathrm{Th}_{0}\right)$ activation, proliferation and IL-2 secretion. Synergistically, IL-36 and IL-12 induce $\mathrm{Th}_{1}$ polarisation through an IL-2-dependent mechanism, whereby IL-2 enhances the expression of the IL-12R on $\mathrm{Th}_{0}$ cells through binding to the alpha chain of IL-2R (CD25). Activation of the IL-12R, in turn, enhances $\mathrm{Th}_{1}$ expression and IFN- $\gamma$ production. Image created with BioRender.com

infiltration in the lower female reproductive tract, increasing resistance against HSV-2 infection and disease [37]. Whilst IL-36y has been shown to have an anti-bacterial function in the lung in one model of bacterial pneumonia by driving protective type- 1 responses and classical macrophage activation [38], in a second model involving Pseudomonas aeruginosa, IL-36 $\gamma$ induced the production of prostaglandin $\mathrm{E} 2\left(\mathrm{PGE}_{2}\right)$ and impaired bacterial clearance, possibility in a $\mathrm{PGE}_{2}$-dependent manner [39]. Conversely, IL-36 $\gamma$ induce autophagy in macrophages infected with Mycobacterium tuberculosis, protecting against infection. The induction of autophagy involved the activation of cyclooxygenase-2, the enzyme responsible of the production of $\mathrm{PGE}_{2}$, although the induction of autophagy did not occur in a $\mathrm{PGE}_{2}$-dependent manner [40]. Finally, whilst IL-36 $\gamma$ has recently been shown to be directly upregulated by both fungal and bacterial epithelial microbes, it is only liberated from cells, and subsequently processed to its mature, potent, pro-inflammatory form, by pathogen-mediated cell damage and pathogenderived proteases. These authors concluded that not only does IL-36 $\gamma$ function as a global epithelial alarmin and 
broad sensor of pathogenic infection, but as it requires activation from pathogenic proteases to be active, that it is a key cytokine in host discrimination between commensals and pathogenic bacteria [41].

\section{The role of IL-36 in the pathogenesis of Inflammatory diseases}

Given the importance of IL-36 cytokines in regulating inflammatory responses, recent studies have explored the pathophysiology function of IL-36 in multiple diverse disease states.

\section{IL-36 in psoriasis}

A pathological role for IL-36 was initially characterised in skin inflammatory diseases and has now been extensively investigated in psoriasis (reviewed in detail here [42]. In psoriatic lesions, elevated IL-36 $\gamma$ and reduced IL-36Ra expression levels have been observed [43, 44]. In psoriatic lesions, IL-36 cytokines can amplify psoriasis pathogenesis by regulating the IL-23/IL-17/IL-22 axis. This axis can enhance the infiltration of neutrophils and promote IL17-producing $\mathrm{T}$ cells, $\mathrm{Th}_{17}$ cells and $\gamma \delta \mathrm{T}$ cells [45]. Of note, these studies demonstrated that the induction of imiqimodinduced psoriasis was directly dependent on IL-36R signalling in keratinocytes and not in haematopoietic cells [45, 46]. Similarly, studies have also demonstrated that psoriatic lesions express significant levels of IL-36 $\alpha$ and this is correlated with increased production of $\mathrm{Th}_{1}$ and $\mathrm{Th}_{17}$ cytokines,

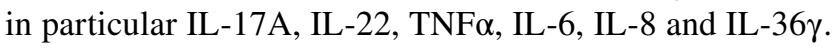
These cytokines can then function in an autocrine manner stimulating IL-36 signalling to produce antimicrobial peptides and pro-inflammatory cytokines [47]. In the skin, IL-36 cytokines stimulate a predominant $\mathrm{Th}_{17}$ cell phenotype which is a major contributor to skin disease [42]. In terms of treatment, anti-TNF $\alpha$ therapy and IL-36R monoclonal antibodies have been sufficient in reducing IL-36 levels and improving psoriasis patient prognosis [48].

Loss-of-function mutations in the IL-36Ra gene, IL36RN, define a recessively inherited autoinflammatory disease named "deficiency of IL-36Ra" (DITRA) [49]. DITRA was first described in a subgroup of patients with generalised

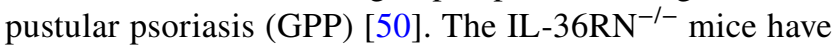
been used to generate a mouse model of DITRA with these mice displaying a delayed skin wound healing response, increased immune cell infiltration and increased levels of pro-inflammatory cytokines [51]. TAK-242, a TLR4 inhibitor, was found to abrogate the delayed skin wound healing response in IL-36 $\mathrm{RN}^{-/-}$mice [52]. Additional studies using IL-36RN ${ }^{-/-}$have highlighted the role of neutrophil extracellular traps (NETs) in psoriasis pathogenesis. In these mice, NETs have been shown to alter IL-36 processing and promote TLR pathways that are PAD4 dependent. PAD4 is a histone-modifying enzyme that is involved in NET formation IL-36 $\mathrm{RN}^{-1-}$ mice treated with the PAD4-inhibitor, $\mathrm{Cl}$-amidine, display reduced immune infiltration, epidermis dysplasia and reduced mRNA expression of IL-36 $\gamma$, IL-17, IL-23 and CXCL-1 [53]. This suggests that NETs may be a potential target in treating psoriatic lesions with DITRA.

Targeting IL-36-mediated inflammation is now an attractive therapy for psoriasis. The vitamin D3 analogue, calcipotriol, alone or in combination with corticosteroids, inhibits keratinocyte proliferation and reduces IL-36 $\alpha / \gamma$ levels in psoriatic patients. Using psoriasis-induced models, calcipotriol was shown to inhibit the mRNA expression of IL-17, IL-23 and IL-36 cytokines and this activity was predominantly dependent on the vitamin D receptor localised in the keratinocytes [54]. Most recently, administration of the monoclonal antibody "Spesolimab" (BI-655130) significantly improved GPP patient outcomes by targeting IL-36R. In phase I clinical trials, BI-655130 administration drastically improved GPP patient's skin symptoms by $80 \%$ [55], with Spesolimab also showing positive effects in phase II trials for palmoplantar pustulosis [56]. In addition to directly targeting the IL-36R, there is evidence emerging that the upstream activators of IL-36 cytokines, namely the proteases Cathepsin $\mathrm{G}$ and elastase, also represent possible therapeutic targets for this disease. Peptide-based pseudosubstrates for cathepsin $\mathrm{G}$ and elastase have been developed based on optimal substrate cleavage motifs which can antagonise the activation of all three IL-36 family cytokines. Processing of IL-36 cytokines by psoriatic skin eluates was by pseudosubstrates for neutrophil protease [57]. In conclusion, IL-36 agonists and IL-36R signalling can regulate skin homeostasis and potentially act as therapeutic targets in skin inflammatory diseases.

\section{IL-36 in inflammatory bowel disease (IBD)}

Like psoriasis, the role of IL-36 in intestinal wound healing and intestinal inflammatory pathologies has now been comprehensively explored. Various studies have highlighted a role for IL-36 in the inflammatory bowel diseases, Crohn's disease (CD) and ulcerative colitis (UC).

Within the intestinal mucosa of patients with UC, IL-36 $\alpha$ and IL-36 $\gamma$ levels are elevated; whereas, IL-36Ra levels are attenuated, indicating a potential pathological role of IL36R signalling in UC [7, 28, 58-60]. In intestinal mucosal lesions of IBD patients, in particular UC, IL-36 $\alpha / \gamma$ protein expression is increased in the epithelial and lamina propria mononuclear cells (LPCs) [58, 59]. In addition, IL-36 $\alpha$ and IL-36 $\gamma$ induced the expression of numerous chemokines and acute phase proteins in colonic epithelial cells in vitro, and this pro-inflammatory response may play an important role 
in the pathogenesis of UCs [58]. As the epithelial barrier function becomes disrupted in inflammatory intestinal diseases, interactions between IL-36 and the intestinal microbiota have been examined. Whilst studies have elucidated that germ-free mice do not induce IL-36y expression upon DSS-induced damage [28], a reciprocal interaction between IL-36 and the intestinal microbiota has been observed. IL-36RN-deficient mice show an altered microbiota, with an increased abundance of the protective bacteria Akkermansia muciniphila in the intestinal microbiome found in these mice (Giannoudaki, 2019 \#57)].

In contrast to DSS models, which are an acute innate model of colon injury, the Citrobacter rodentium $(C$. rodentium) model of colitis can examine mucosal inflammation involving both innate and adaptive responses. Using C. rodentium infected mice, IL-36R signalling was shown to play a critical role in driving early IL-23- and late IL6-mediated IL-22 production, antimicrobial activity, promoting bacterial clearance and host protection [61]. Alterations in T helper cell responses were also detected using this model, with elevated levels of $\mathrm{Th}_{17}$ and reduced levels of $\mathrm{Th}_{1}$ cytokines present in $C$. rodentium infected IL-36 $\mathrm{R}^{-/-}$mice [59]. In conclusion IL-36 can promote colonic inflammation, wound healing and contribute to intestinal inflammatory diseases such as IBD and UC.

Several studies have indicated that fibrotic alterations contribute to intestinal bowel diseases [62] and a role for IL-36 in intestinal fibrosis has now been demonstrated. In tissues from patients with fibrostenotic CD, significantly higher levels of IL36 $\alpha$ were detected. Using the DSS model of colitis, IL-36 $\alpha$ was shown to regulate intestinal fibrosis by inducing IL-36R activity and $\alpha$-SMA ${ }^{+}$myofibroblasts expansion [63]. IL-36R neutralising antibodies, in turn, suppressed fibrosis and reduced the number of activated fibroblasts in the intestine. Indeed, clinic trials using the IL-36R blocking monoclonal antibody BI-655130 in patients with fistulising CD ((NCT03752970) and in patients with UC who have previously failed other biological therapy (NCT03482635) patients are ongoing.

\section{IL-36 in arthritis and joint disorders}

The pathological function of IL-36 cytokines has been investigated in several inflammatory joint disorders such as psoriasis arthritis (PsA), rheumatoid arthritis (RA) and osteoarthritis (OA). Whilst elevated expression of IL-36 $\alpha$ and reduced expression of IL-36Ra have been reported to be associated with OA [64], variation in expression of IL-36 in different types of arthritis has also been identified, with IL-36 $\alpha$ being found to be expressed at a higher level in PsA and RA as compared to OA [65]. In human synovial fibroblast cell lines, IL-36 $\alpha$ induces the activation of MAP kinases and NF- $\mathrm{KB}$, leading to the proliferation of synoviocytes and enhanced expression of pro-inflammatory cytokines and matrix metalloproteases (MMPs). Consistent with this, IL-36R ${ }^{-1-}$-deficient synoviocytes display reduced proliferation and cytokine production in response to IL-36 $\alpha$, and had a limited capacity to support the survival of plasma cells [66].

As with psoriasis and IBD, work has begun examining the potential of developing the IL-36R as a therapeutic target in arthritis. In a murine model of osteoarthritis, intra-archaeal injection of IL-36Ra alleviated osteoarthritis by interfering with IL-36R signalling and MMP-13 expression [64]. Moreover, PsA synovium displays a reduced expression of IL-36Ra and IL-38 suggesting that exogenous replacement of these antagonists may be a promising therapeutic intervention strategy for PsA patients [67]. Of note, however, an earlier study reported that treatment of a murine model of collagen-induced arthritis (CIA) with IL-36R blocking antibodies had no effect on the development or severity of CIA, indicating that, at least in this model, arthritis severity is not IL-36R dependent [68].

\section{IL-36 in pulmonary inflammatory conditions}

Increasing evidence has suggested that IL-36 family members contribute to pulmonary inflammation with elevated IL-36R expression detected in bronchial and fibroblastic epithelial cells [3]. IL-36 cytokines mediate pro-inflammatory cytokine and chemokine production in both human lung tissue cells [69] and in the lungs of mice [70]. In terms of inflammatory conditions in the lungs, whilst IL-36 has been shown to be important in host response to influenza infection in the lung [36], IL-36 signalling has also been implicated to have a pathological role in influenza virus-induced pneumonia [71]. Influenza virus induced the expression of IL-36 $\alpha$ in alveolar epithelial cells, whilst IL-36R-deficient mice were protected from influenza virus-induced lung injury and mortality. Decreased mortality was associated with significantly reduced early accumulation of neutrophils and reduced production of pro-inflammatory cytokines and chemokines, indicating that IL-36 ligands can exacerbate lung injury during influenza virus infection [71].

The role of IL-36 in several lung diseases and lung inflammatory conditions has also been investigated. Elevated IL-36 $\alpha / \gamma$ levels have been detected in patients with asthma and chronic obstructive pulmonary disease (COPD) [72].

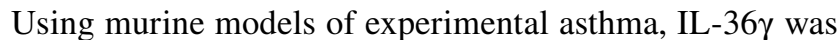
increased in the lungs of mice following sensitisation and challenge with the house dust mite, as well as in $\mathrm{A} / \mathrm{J}$ mice following challenge with OVA [73, 74]. Expression of both IL-36Ra [75] and IL-38 [76] was shown to be reduced in paediatric asthmatic patients, and most recently administration of the IL-36Ra alleviated airway inflammation in a mouse model of asthma [75]. Similarly, a role for IL-36 in 
promoting a pro-inflammatory environment in the lungs of long-term smokers with and without COPD has been identified. IL-36 $\alpha$ and IL-36 $\gamma$ are enhanced systemically and locally in long-term smokers with and without COPD, and local IL-36 $\alpha$ concentrations display a positive correlation with declining ventilatory lung function and increasing proinflammatory cytokine concentrations [77]. Mechanistically, at least some of the pathogenic effect of IL-36 in the lung appears to be via recruitment of neutrophils. Neutrophilic accumulation in the lungs has long been known to be associ-

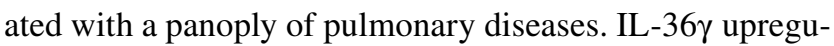
lates neutrophilic chemokines, CXCL-1 and CXCL2, and induces neutrophilic influx in the bronchoalveolar lavage fluid [78]. Pulmonary neutrophils have been shown to be a source of IL-36 and using several murine models of lung inflammation IL-36 was identified as a critical upstream amplifier of neutrophilic lung inflammation in mice [79]. Given that neutrophils also contain the proteases necessary for IL-36 activation, it is evident that a pathological loop may exist with respect to IL-36 action in the lung, whereby lung damage upregulates expression of the IL-36R and IL-36 cytokines, resulting in the recruitment of neutrophils, and the subsequent enhancement of IL-36 activation, which then contributes to the pathological condition.

\section{IL-36 in brain inflammatory disorders including neurodegenerative diseases}

A potential role for IL-36 in Hirschsprung's disease, a genetic disorder characterised by absence of ganglions in the infant bowel, has been identified. Compared to healthy controls, IL-36 $\gamma$ levels were elevated and IL-36R expression was decreased in the colon of affected infants. Given the role of IL-36 in intestinal wound healing, it was suggested that this change in expression could result in persistent pro-inflammatory responses, leading to enterocolitis susceptibility in Hirschsprung's disease affected infants [80]. IL-36 expression has also been observed to be altered in both myasthenia gravis and neuromyelitis optica spectrum disorder $[81,82]$.These findings indicate that IL-36 may merit further investigation in brain and neurological diseases.

\section{IL-36 in renal injury and inflammatory diseases}

IL-36 has recently been identified as a central mediator of renal inflammatory diseases. Compared to healthy controls, elevated IL-36 $\alpha$ levels and IL-36R activity in murine models of unilateral ureteral obstruction have been identified. IL-36 cytokines mediate tubular kidney lesions by enhancing NLRP3 inflammasome activity and promoting $\mathrm{Th}_{17}$ cytokine production [83]. In addition, elevated IL-36 $\alpha$ expression has been associated with proteinuria, fibrosis score and tubulointerstitial lesions which are attributes of renal interstitial fibrosis. Moreover, enhanced expression levels of IL-36R and IL-36 $\alpha$ were observed in the proximal tubules of renal ischaemia-reperfusion injury models. In a murine model of chronic glomerulonephritis, elevated IL-36 $\alpha$ mRNA expression promoted interstitial fibrosis, urinary casts and mononuclear cell infiltration [84]. Most recently, it has been demonstrated that in IL-36R knockout mice, plasma creatinine, blood urea nitrogen, and IL-6 levels after ischaemia-reperfusion injury were significantly lower than those in wild-type mice. Finally, IL-36a level were increased in the urine of patients with acute kidney injury. IL-36R and IL-36 $\alpha$ may act, therefore, as therapeutic targets or potential biomarkers for early renal disease detection and treatment [85].

\section{IL-36 family members in cancer}

Given that inflammation is now recognised as a hallmark of cancer, it is not surprising that IL-36 is now being increasingly investigated in, and implicated in, multiple cancer types. Initial studies investigated the role of IL-36 $\gamma$ in melanoma and metastatic breast cancer using in vivo murine models. B16 melanoma cells were engineered to overex-

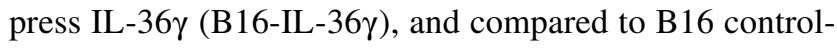
injected mice, B16-IL-36 $\gamma$-injected CB57/BL6 mice displayed reduced tumour growth and improved prognosis [86]. Using a similar model involving the 4T1 breast cancer cell line, IL-36 $\gamma$ overexpression promoted $\mathrm{Th}_{1}$ anti-tumorigenic responses, reduced tumour size and reduced the number of metastatic pulmonary lesions. The IL-36 $\gamma$-mediated antitumorigenic response was characterised by a reduction in tumour-promoting $\mathrm{B}$ cells, a reduction in $\mathrm{Gr}^{+}{ }^{+}$neutrophilic MDSCs, enhanced expression of MHC class II molecules across all MDSC subsets, and increased infiltration of $\mathrm{CD} 8^{+}$ lymphocytes and NK cells into the tumours. IL-36 $\gamma$ also promoted the activation and proliferation of $\mathrm{CD} 8^{+}$cells and NK cells [86]. More recently, the anti-tumorigenic effects of IL-36 $\beta$ was examined in B16 and 4T1 cells in vivo and similar findings were observed, although in this study the ability of IL-36 $\beta$ to promote the activation of $\mathrm{CD}^{+} \mathrm{T}$ cells shown to be dependent on mTORC1 activation. [87].

The expression of IL-36 family members has now been assessed in multiple cancer types. Analysis of online databases

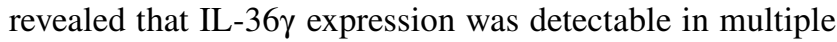
cancers such as lung, colorectal and oesophageal cancer [86]. Several studies have examined the expression of IL-36 family members in hepatocellular carcinoma (HCC) patients. $\mathrm{Hu}$ et al. reported increased IL-36 $\gamma$ production in serum samples from patients with disease, with samples taken from healthy, chronic hepatitis and HCC patients. These studies showed that elevated IL-36 $\gamma$ expression was associated with improved clinicopathological factors, including reduced cirrhosis and metastases [88, 89]. In contrast, a separate report examined 
a cohort of colorectal cancer (CRC) patients for the expression and potential role of IL-36 cytokines in CRC and showed that in patients with CRC, low levels of IL-36 $\gamma$ (IL-36 $\gamma^{\text {low }}$ ) correlated with better patient prognosis. Of note, however, in the same study, elevated expression of IL-36 $\left(\right.$ IL-36 $\alpha^{\text {high }}$ ) was shown to be associated with better patient prognosis and increased $\mathrm{CD}^{+}$and $\mathrm{CD} 8^{+} \mathrm{T}$-cell infiltration. This study highlighted that IL-36 $\alpha^{\text {high }}$ and IL-36 $\gamma^{\text {low }}$ expression levels were correlated with improved clinicopathological parameters and could act as potential biomarkers for CRC, possibly indicating variation between the cytokine members in terms of their role in cancer [90].

In terms of the functional role of IL-36 in the context of tumorigenesis, some in vitro work has been performed to examine the role of IL-36 in tumorigenic processes, with IL-36 $\alpha$ shown to suppress tumour proliferation, invasion and migration in SKOV-3 and OV2008 epithelial ovarian cancer cell lines [91]. A clear function for IL-36 has been identified in tertiary lymphoid organ (TLO) formation. TLOs trigger antitumorigenic responses by promoting DC-mediated tumour antigen presentation and T-cell priming [92]. Initial studies demonstrated that elevated IL-36 $\gamma$ expression was associated with TLO formation, enhanced CD20 ${ }^{+} \mathrm{B}$ cells and $\mathrm{CD} 4^{+}$ memory T-cell infiltration and overall better patient prognosis [93]. The injection of tumours with DCs engineered to secrete

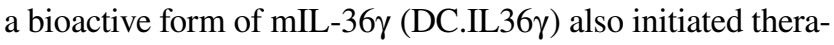
peutic TLO and slowed tumour progression in vivo. DC.IL36y cells strongly upregulated their expression of Tbet, suggesting that Tbet and IL-36 $\gamma$ cooperate to reinforce each other's expression in DC, rendering them competent to promote TLO formation [94]. In addition to the generation of TLOs, the ability of IL-36 cytokines to promote an anti-tumorigenic immune response has been further reinforced by recent findings showing that IL-36 $\beta$ can enhance CD8 ${ }^{+}$T-cell proliferation and activation [87]. The role of IL-36 $\beta$ in $\mathrm{CD}^{+} \mathrm{T}$ cells is dependent on the ability of this cytokine to induce the long noncoding RNA GM16343. Synergistically, GM16343 and IL-36 $\beta$ induce an anti-tumorigenic immune response by enhancing IFN- $\gamma$ production in $\mathrm{CD}^{+} \mathrm{T}$-lymphocytes. Tumoral expression of GM16343 was also shown to reduce tumour size and improve prognosis in mice injected with CT-26 colon tumour cells [95]. Overall, therefore, the mechanism of action of IL-36 in driving tumour suppressive effects appears to be via modification of the tumour microenvironment (TME) and the promotion of an anti-tumorigenic immune response (Fig. 3).

\section{Emerging role for IL-36 as a cancer immunotherapy?}

Since Coley's success story in 1893, advancements in immunotherapies have revolutionised treatments for cancer patients. Whilst immune checkpoint inhibitors have

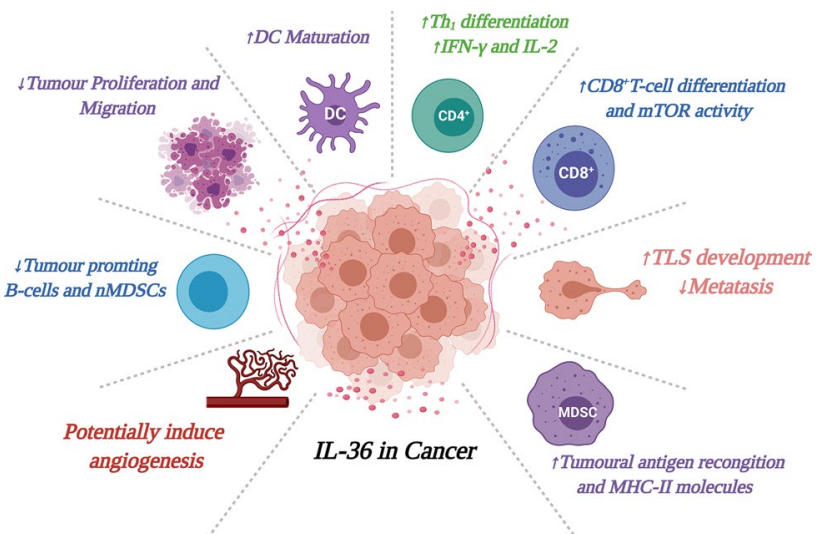

Fig. 3 IL-36 can induce an anti-tumorigenic immune response in cancer. IL-36 can promote $\mathrm{Th}_{1}$ differentiation and IFN- $\gamma$ production in $\mathrm{CD} 4^{+}, \mathrm{CD}^{+}$and NK cells, DC maturation, TLS formation, MHC-II expression in MDSCs. IL-36 can also suppress tumour cell migration and invasion, and suppress infiltration by tumour-promoting B cells and nMDSCs. The resultant effect is the reduction in tumour cell proliferation and metastasis. Recent studies have shown that IL-36 also has the potential to induce angiogenesis in cancer. Image created with BioRender.com

revolutionised the main standard of care for many cancer types, the majority of patients do not benefit from these treatments (i.e. intrinsic resistance), and some responders relapse after a period of response (i.e. acquired resistance).

Increasing evidence has shown that IL-36 $\gamma$ co-delivered with other TME-altering therapeutics could represent an effective combination therapy. Using the 4T1 metastatic breast cancer cell line, IL-36 $\gamma$ and doxorubicin (Dox) codelivered using POEG-st-Pmor polymers suppressed tumour growth and the development of lung metastasis [96]. In murine colon cancer models, IL-36y co-administrated with OX40L and IL-23 greatly improved tumour susceptibility to immune checkpoint blockade therapy [97]. As demonstrated by Wang et al., IL-36 $\gamma$ can have anti-tumorigenic properties, and therefore tumoral expression of IL-36 $\gamma$ could act as an effective tumour vaccine approach [86]. In vivo studies have shown that IL-36 $\gamma$ can also promote $\mathrm{Th}_{1}$ responses in $\mathrm{CD}^{+}$ T-cells using an experimental model of Bacillus CalmetteGuerin (BCG) infection [4]. Together these findings indicate an increasing potential for IL-36 $\gamma$ to be integrated into various anticancer vaccines.

Evidence is now emerging concerning cross-talk between IL-36 cytokines and immune checkpoint inhibitor proteins. Expression of the IL-36Ra was associated with intratumoral expression of checkpoint molecules, including PD-1, PD-L1, and CTLA-4 in colorectal tumours [93]. In lung adenocarcinoma, it has been observed that the PD-L1-positive cases show higher expression of the IL-36 inhibitor, IL-38, as compared to PD-L1-negative cases [98]. Most recently, cooperation between IL-36 and anti-CTLA-4 mAbs has been 
observed to enhance tumour eradication and reduce lung metastasis as compared to CTLA- 4 mABs alone. These authors generated nanoparticles loaded with IL-36 and administered these nanoparticles to mice injected intradermally with B 16 breast cancer cells with or without antiCTLA-4 mAbs. The combination drove an enhanced Type 1 immune response, whilst also increasing the number of $\mathrm{T}$ regulatory cells found within the tumours [99].

\section{Future perspectives for IL-36 therapies in cancer}

Taken together, the above findings indicate that IL-36 signalling appears to be a very promising signalling pathway to manipulate for both certain inflammatory conditions and for improved cancer patient outcomes. It is clear that significant work is underway by several groups to develop sophisticated therapies for IL-36 delivery to tumours using both nanotechnological solutions and loading of immune cells with IL-36 cytokines for improved efficacy and delivery. In particular, the recent findings concerning co-treatment of tumours with IL-36 cytokines and either standard of care chemotherapy/ novel immunotherapies show great promise and are worthy of future development.

It seems prudent, however, at this point to reflect on what we have learnt about the wider family of IL-1 cytokines in tumorigenesis, prior to embracing IL-36 as an antitumorigenic cytokine. Chronic inflammation has long been identified to be a contributing factor in cancer development. In the recent CANTOS trial, inhibition of IL- $1 \beta$ using canakinumab, a human anti-IL-1 $\beta$ monoclonal antibody, significantly reduced lung cancer incidence in a cohort of 10,061 patients with prior myocardial infarction [100]. An independent cohort of 47 patients with smoldering/indolent myeloma, treated for six months with the IL-1R antagonist anakinra and low dose of dexamethasone, displayed progression-free disease that lasted over 3 years and, and in 8 patients, even over 4 years [101]. Indeed all other members of the IL-1 family have been shown to have tumour promoting as well as tumour inhibiting properties, depending on the cancer type and the expression level [102]. Indeed, with respect to IL-36, many classical tumour-promoting properties have already been assigned to these cytokines and discussed in other contexts in this review, such as an ability to enhance cellular proliferation $[4,31]$, cellular migration [103] and driving fibrosis [63]. In addition, IL-36 family members have recently been reported to promote angiogenesis, an essential factor for tumour growth [103, 104] (Fig. 3).

In conclusion, therefore, whilst there appears to be therapeutic potential for IL-36 cytokines in several diseases including cancer, much remains to be identified concerning this complex cytokine family and its multifaceted effects on diverse cell types prior to this potential being realised.

Author contributions $\mathrm{JB}, \mathrm{KB}, \mathrm{AH}$ and $\mathrm{EB}$ all contributed to the writing and design of the article. JB prepared the figures. KB/EB obtained the funding.

Funding Open Access funding provided by the IReL Consortium. This work was supported by funding from the Irish Research Council grant code GOIPG/2018/2974.

Availability of data and material As this is a review article, there is no requirement for data availability.

\section{Declarations}

Conflict of interest The authors have no competing of interests to declare.

Ethics approval and consent to participate As this is a review article, no ethical approval was necessary.

Consent for publication All authors have confirmed consent for publication.

Open Access This article is licensed under a Creative Commons Attribution 4.0 International License, which permits use, sharing, adaptation, distribution and reproduction in any medium or format, as long as you give appropriate credit to the original author(s) and the source, provide a link to the Creative Commons licence, and indicate if changes were made. The images or other third party material in this article are included in the article's Creative Commons licence, unless indicated otherwise in a credit line to the material. If material is not included in the article's Creative Commons licence and your intended use is not permitted by statutory regulation or exceeds the permitted use, you will need to obtain permission directly from the copyright holder. To view a copy of this licence, visit http://creativecommons.org/licenses/by/4.0/.

\section{References}

1. Dunn E, Sims JE, Nicklin MJ, O’Neill LA (2001) Annotating genes with potential roles in the immune system: six new members of the IL-1 family. Trends Immunol 22:533-536

2. Dinarello C, Arend W, Sims J, Smith D, Blumberg H, O'Neill L, Goldbach-Mansky R, Pizarro T, Hoffman H, Bufler P, Nold M, Ghezzi P, Mantovani A, Garlanda C, Boraschi D, Rubartelli A, Netea M, van der Meer J, Joosten L, Mandrup-Poulsen T, Donath M, Lewis E, Pfeilschifter J, Martin M, Kracht M, Muehl H, Novick D, Lukic M, Conti B, Solinger A, Kelk P, van de Veerdonk F, Gabel C (2010) IL-1 family nomenclature. Nat Immunol 11:973

3. Queen D, Ediriweera C, Liu L (2019) Function and regulation of IL-36 signaling in inflammatory diseases and cancer development. Front Cell Dev Biol 7:317

4. Vigne S, Palmer G, Martin P, Lamacchia C, Strebel D, Rodriguez E, Olleros ML, Vesin D, Garcia I, Ronchi F, Sallusto F, Sims JE, Gabay C (2012) IL-36 signaling amplifies Th1 responses by enhancing proliferation and Th1 polarization of naive CD4+ T cells. Blood 120:3478-3487 
5. Gresnigt MS, van de Veerdonk FL (2013) Biology of IL-36 cytokines and their role in disease. Semin Immunol 25:458-465

6. Busfield SJ, Comrack CA, Yu G, Chickering TW, Smutko JS, Zhou H, Leiby KR, Holmgren LM, Gearing DP, Pan Y (2000) Identification and gene organization of three novel members of the IL-1 family on human chromosome 2 . Genomics 66:213-216

7. Ding L, Wang X, Hong X, Lu L, Liu D (2018) IL-36 cytokines in autoimmunity and inflammatory disease. Oncotarget 9:2895-2901

8. Martin U, Scholler J, Gurgel J, Renshaw B, Sims JE, Gabel CA (2009) Externalization of the leaderless cytokine IL-1F6 occurs in response to lipopolysaccharide/ATP activation of transduced bone marrow macrophages. J Immunol 183:4021-4030

9. Henry CM, Sullivan GP, Clancy DM, Afonina IS, Kulms D, Martin SJ (2016) Neutrophil-derived proteases escalate inflammation through activation of IL-36 family cytokines. Cell Rep 14:708-722

10. Dietrich D, Martin P, Flacher V, Sun Y, Jarrossay D, Brembilla N, Mueller C, Arnett HA, Palmer G, Towne J, Gabay C (2016) Interleukin-36 potently stimulates human M2 macrophages, Langerhans cells and keratinocytes to produce pro-inflammatory cytokines. Cytokine 84:88-98

11. Towne JE, Garka KE, Renshaw BR, Virca GD, Sims JE (2004) Interleukin (IL)-1F6, IL-1F8, and IL-1F9 signal through IL1 Rrp2 and IL-1RAcP to activate the pathway leading to NFkappaB and MAPKs. J Biol Chem 279:13677-13688

12. Gunther S, Sundberg EJ (2014) Molecular determinants of agonist and antagonist signaling through the IL-36 receptor. J Immunol 193:921-930

13. Swindell WR, Beamer MA, Sarkar MK, Loftus S, Fullmer J, Xing X, Ward NL, Tsoi LC, Kahlenberg MJ, Liang Y, Gudjonsson JE (2018) RNA-Seq analysis of IL-1B and IL-36 responses in epidermal keratinocytes identifies a shared MyD88-dependent gene signature. Front Immunol 9:80

14. Walsh PT, Fallon PG (2018) The emergence of the IL-36 cytokine family as novel targets for inflammatory diseases. Ann N Y Acad Sci 1417:23-34

15. Jain A, Kaczanowska S, Davila E (2014) IL-1 receptor-associated kinase signaling and its role in inflammation, cancer progression, and therapy resistance. Front Immunol 5:553

16. Dunn EF, Gay NJ, Bristow AF, Gearing DP, O’Neill LA, Pei XY (2003) High-resolution structure of murine interleukin 1 homologue IL-1F5 reveals unique loop conformations for receptor binding specificity. Biochemistry 42:10938-10944

17. van de Veerdonk FL, Stoeckman AK, Wu G, Boeckermann AN, Azam T, Netea MG, Joosten LA, van der Meer JW, Hao R, Kalabokis V, Dinarello CA (2012) IL-38 binds to the IL-36 receptor and has biological effects on immune cells similar to IL-36 receptor antagonist. Proc Natl Acad Sci USA 109:3001-3005

18. Costelloe C, Watson M, Murphy A, McQuillan K, Loscher C, Armstrong ME, Garlanda C, Mantovani A, O'Neill LA, Mills KH, Lynch MA (2008) IL-1F5 mediates anti-inflammatory activity in the brain through induction of IL-4 following interaction with SIGIRR/TIR8. J Neurochem 105:1960-1969

19. Han Y, Mora J, Huard A, da Silva P, Wiechmann S, Putyrski M, Schuster C, Elwakeel E, Lang G, Scholz A, Scholz T, Schmid T, de Bruin N, Billuart P, Sala C, Burkhardt H, Parnham MJ, Ernst A, Brune B, Weigert A (2019) IL-38 ameliorates skin inflammation and limits IL-17 production from gammadelta T Cells. Cell Rep 27:835-846

20. Xie L, Huang Z, Li H, Liu X, Zheng S, Su W (2019) IL-38: a new player in inflammatory autoimmune disorders. Biomolecules 9(8):345

21. Blumberg H, Dinh H, Trueblood ES, Pretorius J, Kugler D, Weng N, Kanaly ST, Towne JE, Willis CR, Kuechle MK, Sims JE,
Peschon JJ (2007) Opposing activities of two novel members of the IL-1 ligand family regulate skin inflammation. J Exp Med 204:2603-2614

22. Scheibe K, Backert I, Wirtz S, Hueber A, Schett G, Vieth M, Probst HC, Bopp T, Neurath MF, Neufert C (2017) IL-36R signalling activates intestinal epithelial cells and fibroblasts and promotes mucosal healing in vivo. Gut 66:823-838

23. Lai Y, Li D, Li C, Muehleisen B, Radek KA, Park HJ, Jiang Z, Li Z, Lei H, Quan Y, Zhang T, Wu Y, Kotol P, Morizane S, Hata TR, Iwatsuki K, Tang C, Gallo RL (2012) The antimicrobial protein REG3A regulates keratinocyte proliferation and differentiation after skin injury. Immunity 37:74-84

24. Jiang Z, Liu Y, Li C, Chang L, Wang W, Wang Z, Gao X, Ryffel B, Wu Y, Lai Y (2017) IL-36gamma induced by the TLR3SLUG-VDR axis promotes wound healing via REG3A. J Investig Dermatol 137:2620-2629

25. Franzke CW, Cobzaru C, Triantafyllopoulou A, Loffek S, Horiuchi K, Threadgill DW, Kurz T, van Rooijen N, BrucknerTuderman L, Blobel CP (2012) Epidermal ADAM17 maintains the skin barrier by regulating EGFR ligand-dependent terminal keratinocyte differentiation. J Exp Med 209:1105-1119

26. Yang J, Meyer M, Muller AK, Bohm F, Grose R, Dauwalder T, Verrey F, Kopf M, Partanen J, Bloch W, Ornitz DM, Werner S (2010) Fibroblast growth factor receptors 1 and 2 in keratinocytes control the epidermal barrier and cutaneous homeostasis. J Cell Biol 188:935-952

27. Kanda T, Nishida A, Takahashi K, Hidaka K, Imaeda H, Inatomi O, Bamba S, Sugimoto M, Andoh A (2015) Interleukin(IL)36alpha and IL-36gamma induce proinflammatory mediators from human colonic subepithelial myofibroblasts. Front Med (Lausanne) 2:69

28. Medina-Contreras O, Harusato A, Nishio H, Flannigan KL, Ngo V, Leoni G, Neumann PA, Geem D, Lili LN, Ramadas RA, Chassaing B, Gewirtz AT, Kohlmeier JE, Parkos CA, Towne JE, Nusrat A, Denning TL (2016) Cutting edge: IL-36 receptor promotes resolution of intestinal damage. J Immunol 196:34-38

29. Ngo VL, Abo H, Maxim E, Harusato A, Geem D, Medina-Contreras O, Merlin D, Gewirtz AT, Nusrat A, Denning TL (2018) A cytokine network involving IL-36gamma, IL-23, and IL-22 promotes antimicrobial defense and recovery from intestinal barrier damage. Proc Natl Acad Sci USA 115:E5076-E5085

30. Mutamba S, Allison A, Mahida Y, Barrow P, Foster N (2012) Expression of IL-1Rrp2 by human myelomonocytic cells is unique to DCs and facilitates DC maturation by IL-1F8 and IL-1F9. Eur J Immunol 42:607-617

31. Foster AM, Baliwag J, Chen CS, Guzman AM, Stoll SW, Gudjonsson JE, Ward NL, Johnston A (2014) IL-36 promotes myeloid cell infiltration, activation, and inflammatory activity in skin. J Immunol 192:6053-6061

32. Penha R, Higgins J, Mutamba S, Barrow P, Mahida Y, Foster N (2016) IL-36 receptor is expressed by human blood and intestinal $\mathrm{T}$ lymphocytes and is dose-dependently activated via IL-36beta and induces CD4+ lymphocyte proliferation. Cytokine 85:18-25

33. Harusato A, Abo H, Ngo VL, Yi SW, Mitsutake K, Osuka S, Kohlmeier JE, Li JD, Gewirtz AT, Nusrat A, Denning TL (2017) IL-36gamma signaling controls the induced regulatory $\mathrm{T}$ cellTh9 cell balance via NFkappaB activation and STAT transcription factors. Mucosal Immunol 10:1455-1467

34. Chen J, Guan L, Tang L, Liu S, Zhou Y, Chen C, He Z, Xu L (2019) T helper 9 cells: a new player in immune-related diseases. DNA Cell Biol 38:1040-1047

35. Wang P, Gamero AM, Jensen LE (2019) IL-36 promotes antiviral immunity by boosting sensitivity to IFN-alpha/beta in IRF1 dependent and independent manners. Nat Commun 10:4700

36. Wein AN, Dunbar PR, McMaster SR, Li ZT, Denning TL, Kohlmeier JE (2018) IL-36gamma protects against severe 
influenza infection by promoting lung alveolar macrophage survival and limiting viral replication. J Immunol 201:573-582

37. Gardner JK, Herbst-Kralovetz MM (2018) IL-36gamma induces a transient HSV-2 resistant environment that protects against genital disease and pathogenesis. Cytokine 111:63-71

38. Kovach MA, Singer B, Martinez-Colon G, Newstead MW, Zeng X, Mancuso P, Moore TA, Kunkel SL, Peters-Golden M, Moore BB, Standiford TJ (2017) IL-36gamma is a crucial proximal component of protective type-1-mediated lung mucosal immunity in Gram-positive and -negative bacterial pneumonia. Mucosal Immunol 10:1320-1334

39. Aoyagi T, Newstead MW, Zeng X, Nanjo Y, Peters-Golden M, Kaku M, Standiford TJ (2017) Interleukin-36gamma and IL-36 receptor signaling mediate impaired host immunity and lung injury in cytotoxic Pseudomonas aeruginosa pulmonary infection: role of prostaglandin E2. PLoS Pathog 13:e1006737

40. Gao Y, Wen Q, Hu S, Zhou X, Xiong W, Du X, Zhang L, Fu Y, Yang J, Zhou C, Zhang Z, Li Y, Liu H, Huang Y, Ma L (2019) IL-36gamma promotes killing of Mycobacterium tuberculosis by macrophages via WNT5A-induced noncanonical WNT signaling. J Immunol 203:922-935

41. Macleod T, Ainscough JS, Hesse C, Konzok S, Braun A, Buhl AL, Wenzel J, Bowyer P, Terao Y, Herrick S, Wittmann M, Stacey M (2020) The Proinflammatory cytokine IL-36gamma is a global discriminator of harmless microbes and invasive pathogens within epithelial tissues. Cell Rep 33:108515

42. Madonna S, Girolomoni G, Dinarello CA, Albanesi C (2019) The significance of IL-36 hyperactivation and IL-36R targeting in psoriasis. Int J Mol Sci 20(13):3318

43. D'Erme AM, Wilsmann-Theis D, Wagenpfeil J, Holzel M, Ferring-Schmitt S, Sternberg S, Wittmann M, Peters B, Bosio A, Bieber T, Wenzel J (2015) IL-36gamma (IL-1F9) is a biomarker for psoriasis skin lesions. J Investig Dermatol 135:1025-1032

44. Boutet MA, Bart G, Penhoat M, Amiaud J, Brulin B, Charrier C, Morel F, Lecron JC, Rolli-Derkinderen M, Bourreille A, Vigne S, Gabay C, Palmer G, Le Goff B, Blanchard F (2016) Distinct expression of interleukin (IL)-36alpha, beta and gamma, their antagonist IL-36Ra and IL-38 in psoriasis, rheumatoid arthritis and Crohn's disease. Clin Exp Immunol 184:159-173

45. Tortola L, Rosenwald E, Abel B, Blumberg H, Schafer M, Coyle AJ, Renauld JC, Werner S, Kisielow J, Kopf M (2012) Psoriasiform dermatitis is driven by IL-36-mediated DC-keratinocyte crosstalk. J Clin Investig 122:3965-3976

46. Lorscheid S, Muller A, Loffler J, Resch C, Bucher P, Kurschus FC, Waisman A, Schakel K, Hailfinger S, SchulzeOsthoff K, Kramer D (2019) Keratinocyte-derived IkappaBzeta drives psoriasis and associated systemic inflammation. JCI Insight 4(22):e130835

47. Carrier Y, Ma HL, Ramon HE, Napierata L, Small C, O'Toole M, Young DA, Fouser LA, Nickerson-Nutter C, Collins M, Dunussi-Joannopoulos K, Medley QG (2011) Inter-regulation of Th17 cytokines and the IL-36 cytokines in vitro and in vivo: implications in psoriasis pathogenesis. J Investig Dermatol 131:2428-2437

48. Bachelez H, Choon SE, Marrakchi S, Burden AD, Tsai TF, Morita A, Turki H, Hall DB, Shear M, Baum P, Padula SJ, Thoma C (2019) Inhibition of the interleukin-36 pathway for the treatment of generalized pustular psoriasis. N Engl J Med 380:981-983

49. Marrakchi S, Guigue P, Renshaw BR, Puel A, Pei XY, Fraitag S, Zribi J, Bal E, Cluzeau C, Chrabieh M, Towne JE, Douangpanya J, Pons C, Mansour S, Serre V, Makni H, Mahfoudh N, Fakhfakh F, Bodemer C, Feingold J, Hadj-Rabia S, Favre M, Genin E, Sahbatou M, Munnich A, Casanova JL, Sims JE, Turki H, Bachelez
H, Smahi A (2011) Interleukin-36-receptor antagonist deficiency and generalized pustular psoriasis. N Engl J Med 365:620-628

50. Sugiura K, Takemoto A, Yamaguchi M, Takahashi H, Shoda Y, Mitsuma T, Tsuda K, Nishida E, Togawa Y, Nakajima K, Sakakibara A, Kawachi S, Shimizu M, Ito Y, Takeichi T, Kono M, Ogawa Y, Muro Y, Ishida-Yamamoto A, Sano S, Matsue H, Morita A, Mizutani H, Iizuka H, Muto M, Akiyama M (2013) The majority of generalized pustular psoriasis without psoriasis vulgaris is caused by deficiency of interleukin-36 receptor antagonist. J Investig Dermatol 133:2514-2521

51. Saito K, Iwata Y, Fukushima H, Watanabe S, Tanaka Y, Hasegawa Y, Akiyama M, Sugiura K (2020) IL-36 receptor antagonist deficiency resulted in delayed wound healing due to excessive recruitment of immune cells. Sci Rep 10:14772

52. Shibata A, Sugiura K, Furuta Y, Mukumoto Y, Kaminuma O, Akiyama M (2017) Toll-like receptor 4 antagonist TAK-242 inhibits autoinflammatory symptoms in DITRA. J Autoimmun 80:28-38

53. Watanabe S, Iwata Y, Fukushima H, Saito K, Tanaka Y, Hasegawa Y, Akiyama M, Sugiura K (2020) Neutrophil extracellular traps are induced in a psoriasis model of interleukin-36 receptor antagonist-deficient mice. Sci Rep 10:20149

54. German B, Wei R, Hener P, Martins C, Ye T, Gottwick C, Yang J, Seneschal J, Boniface K, Li M (2019) Disrupting the IL-36 and IL-23/IL-17 loop underlies the efficacy of calcipotriol and corticosteroid therapy for psoriasis. JCI Insight 4(2):e123390

55. Iznardo H, Puig L (2021) Exploring the role of IL-36 cytokines as a new target in psoriatic disease. Int J Mol Sci 22(9):4344

56. Mrowietz U, Burden AD, Pinter A, Reich K, Schakel K, Baum P, Datsenko Y, Deng H, Padula SJ, Thoma C, Bissonnette R (2021) Spesolimab, an anti-interleukin-36 receptor antibody, in patients with palmoplantar pustulosis: results of a phase IIa, multicenter, double-blind, randomized, placebo-controlled pilot study. Dermatol Ther (Heidelb) 11:571-585

57. Sullivan GP, Henry CM, Clancy DM, Mametnabiev T, Belotcerkovskaya E, Davidovich P, Sura-Trueba S, Garabadzhiu AV, Martin SJ (2018) Suppressing IL-36-driven inflammation using peptide pseudosubstrates for neutrophil proteases. Cell Death Dis 9:378

58. Nishida A, Hidaka K, Kanda T, Imaeda H, Shioya M, Inatomi O, Bamba S, Kitoh K, Sugimoto M, Andoh A (2016) Increased expression of interleukin-36, a member of the interleukin-1 cytokine family, in inflammatory Bowel disease. Inflamm Bowel Dis 22:303-314

59. Russell SE, Horan RM, Stefanska AM, Carey A, Leon G, Aguilera M, Statovci D, Moran T, Fallon PG, Shanahan F, Brint EK, Melgar S, Hussey S, Walsh PT (2016) IL-36alpha expression is elevated in ulcerative colitis and promotes colonic inflammation. Mucosal Immunol 9:1193-1204

60. Fonseca-Camarillo G, Furuzawa-Carballeda J, Iturriaga-Goyon E, Yamamoto-Furusho JK (2018) Differential expression of IL-36 family members and IL-38 by immune and nonimmune cells in patients with active inflammatory Bowel disease. Biomed Res Int 2018:5140691

61. Ngo VL, Abo H, Kuczma M, Szurek E, Moore N, Medina-Contreras O, Nusrat A, Merlin D, Gewirtz AT, Ignatowicz L, Denning TL (2020) IL-36R signaling integrates innate and adaptive immune-mediated protection against enteropathogenic bacteria. Proc Natl Acad Sci USA 117:27540-27548

62. Latella G, Rieder F (2017) Intestinal fibrosis: ready to be reversed. Curr Opin Gastroenterol 33:239-245

63. Scheibe K, Kersten C, Schmied A, Vieth M, Primbs T, Carle B, Knieling F, Claussen J, Klimowicz AC, Zheng J, Baum P, Meyer S, Schurmann S, Friedrich O, Waldner MJ, Rath T, Wirtz S, Kollias G, Ekici AB, Atreya R, Raymond EL, Mbow ML, Neurath MF, Neufert C (2019) Inhibiting interleukin 36 receptor signaling 
reduces fibrosis in mice with chronic intestinal inflammation. Gastroenterology 156:1082-1097 e11

64. Li T, Chubinskaya S, Esposito A, Jin X, Tagliafierro L, Loeser R, Hakimiyan AA, Longobardi L, Ozkan H, Spagnoli A (2019) TGF-beta type 2 receptor-mediated modulation of the IL-36 family can be therapeutically targeted in osteoarthritis. Sci Transl Med 11(491):eaan2585. https://doi.org/10.1126/scitranslmed. aan 2585

65. Frey S, Derer A, Messbacher ME, Baeten DL, Bugatti S, Montecucco C, Schett G, Hueber AJ (2013) The novel cytokine interleukin-36alpha is expressed in psoriatic and rheumatoid arthritis synovium. Ann Rheum Dis 72:1569-1574

66. Schmitt V, Hahn M, Kastele V, Wagner O, Wiendl M, Derer A, Taddeo A, Hahne S, Radbruch A, Jack HM, Schuh W, Mielenz D, Gay S, Schett G, Hueber AJ, Frey S (2017) Interleukin-36 receptor mediates the crosstalk between plasma cells and synovial fibroblasts. Eur J Immunol 47:2101-2112

67. Boutet MA, Nerviani A, Lliso-Ribera G, Lucchesi D, Prediletto E, Ghirardi GM, Goldmann K, Lewis M, Pitzalis C (2020) Interleukin-36 family dysregulation drives joint inflammation and therapy response in psoriatic arthritis. Rheumatology (Oxford) 59:828-838

68. Lamacchia C, Palmer G, Rodriguez E, Martin P, Vigne S, Seemayer CA, Talabot-Ayer D, Towne JE, Gabay C (2013) The severity of experimental arthritis is independent of IL-36 receptor signaling. Arthritis Res Ther 15:R38

69. Zhang J, Yin Y, Lin X, Yan X, Xia Y, Zhang L, Cao J (2017) IL-36 induces cytokine IL-6 and chemokine CXCL8 expression in human lung tissue cells: implications for pulmonary inflammatory responses. Cytokine 99:114-123

70. Ramadas RA, Ewart SL, Iwakura Y, Medoff BD, LeVine AM (2012) IL-36alpha exerts pro-inflammatory effects in the lungs of mice. PLoS ONE 7:e45784

71. Aoyagi T, Newstead MW, Zeng X, Kunkel SL, Kaku M, Standiford TJ (2017) IL-36 receptor deletion attenuates lung injury and decreases mortality in murine influenza pneumonia. Mucosal Immunol 10:1043-1055

72. Chen H, Wang Y, Bai C, Wang X (2012) Alterations of plasma inflammatory biomarkers in the healthy and chronic obstructive pulmonary disease patients with or without acute exacerbation. J Proteom 75:2835-2843

73. Ramadas RA, Ewart SL, Medoff BD, LeVine AM (2011) Interleukin-1 family member 9 stimulates chemokine production and neutrophil influx in mouse lungs. Am J Respir Cell Mol Biol 44:134-145

74. Ramadas RA, Li X, Shubitowski DM, Samineni S, Wills-Karp M, Ewart SL (2006) IL-1 Receptor antagonist as a positional candidate gene in a murine model of allergic asthma. Immunogenetics 58:851-855

75. Liu XG, Li J, Zheng LJ, Han B, Huang F (2020) Interleukin-36 receptor antagonist alleviates airway inflammation in asthma via inhibiting the activation of Interleukin-36 pathway. Int Immunopharmacol 81:106200

76. Chu M, Chu IM, Yung EC, Lam CW, Leung TF, Wong GW, Wong CK (2016) Aberrant expression of novel cytokine IL-38 and regulatory $\mathrm{T}$ lymphocytes in childhood asthma. Molecules 21(7):933. https://doi.org/10.3390/molecules21070933

77. Kovach MA, Che K, Brundin B, Andersson A, Asgeirsdottir H, Padra M, Linden SK, Qvarfordt I, Newstead MW, Standiford TJ, Linden A (2021) IL-36 cytokines promote inflammation in the lungs of long-term smokers. Am J Respir Cell Mol Biol 64:173-182

78. Gabay C, Towne JE (2015) Regulation and function of interleukin-36 cytokines in homeostasis and pathological conditions. $\mathrm{J}$ Leukoc Biol 97:645-652
79. Koss CK, Wohnhaas CT, Baker JR, Tilp C, Przibilla M, Lerner C, Frey S, Keck M, Williams CMM, Peter D, Ramanujam M, Fine J, Gantner F, Thomas M, Barnes PJ, Donnelly LE, El Kasmi KC (2021) IL36 is a critical upstream amplifier of neutrophilic lung inflammation in mice. Commun Biol 4:172

80. Tomuschat C, O’Donnell AM, Coyle D, Puri P (2017) Altered expression of IL36gamma and IL36 receptor (IL1RL2) in the colon of patients with Hirschsprung's disease. Pediatr Surg Int 33:181-186

81. Zhang QX, Li Y, Jiang SM, Zhang LJ, Yi M, Wang J, Qi Y, Yang L, Yang CS (2020) Increased serum IL-36gamma levels are associated with disease severity in myasthenia gravis patients. BMC Neurol 20:307

82. Yang CS, Zhang QX, Deng Y, Zhou BJ, Zhang LJ, Li LM, Qi Y, Wang J, Yang L, Shi FD (2019) Increased serum IL-36beta and IL-36gamma levels in patients with neuromyelitis optica spectrum disorders: association with disease activity. BMC Neurol 19:185

83. Chi HH, Hua KF, Lin YC, Chu CL, Hsieh CY, Hsu YJ, Ka SM, Tsai YL, Liu FC, Chen A (2017) IL-36 signaling facilitates activation of the NLRP3 inflammasome and IL-23/IL-17 axis in renal inflammation and fibrosis. J Am Soc Nephrol 28:2022-2037

84. Ichii O, Otsuka S, Sasaki N, Yabuki A, Ohta H, Takiguchi M, Hashimoto Y, Endoh D, Kon Y (2010) Local overexpression of interleukin-1 family, member 6 relates to the development of tubulointerstitial lesions. Lab Invest 90:459-475

85. Nishikawa H, Taniguchi Y, Matsumoto T, Arima N, Masaki M, Shimamura Y, Inoue K, Horino T, Fujimoto S, Ohko K, Komatsu T, Udaka K, Sano S, Terada Y (2018) Knockout of the interleukin-36 receptor protects against renal ischemiareperfusion injury by reduction of proinflammatory cytokines. Kidney Int 93:599-614

86. Wang X, Zhao X, Feng C, Weinstein A, Xia R, Wen W, Lv Q, Zuo S, Tang P, Yang X, Chen X, Wang H, Zang S, Stollings L, Denning TL, Jiang J, Fan J, Zhang G, Zhang X, Zhu Y, Storkus W, Lu B (2015) IL-36gamma transforms the tumor microenvironment and promotes type 1 lymphocyte-mediated antitumor immune responses. Cancer Cell 28:296-306

87. Zhao X, Chen X, Shen X, Tang P, Chen C, Zhu Q, Li M, Xia R, Yang X, Feng C, Zhu X, Zhu Y, Sun Z, Zhang X, Lu B, Wang $X$ (2019) IL-36beta promotes CD8(+) T cell activation and antitumor immune responses by activating mTORC1. Front Immunol 10:1803

88. Hu M, Tong Y, Fang H, Tang J, Liu L, Hu Y, Li J, Zhong L (2020) IL36 indicating good prognosis in human hepatocellular carcinoma. J Cancer 11:6248-6255

89. Pan QZ, Pan K, Zhao JJ, Chen JG, Li JJ, Lv L, Wang DD, Zheng HX, Jiang SS, Zhang XF, Xia JC (2013) Decreased expression of interleukin-36alpha correlates with poor prognosis in hepatocellular carcinoma. Cancer Immunol Immunother 62:1675-1685

90. Chen F, Qu M, Zhang F, Tan Z, Xia Q, Hambly BD, Bao S, Tao $\mathrm{K}$ (2020) IL-36 s in the colorectal cancer: is interleukin 36 good or bad for the development of colorectal cancer? BMC Cancer 20:92

91. Chang L, Guo R, Yuan Z (2017) IL-36alpha suppresses proliferation of ovarian cancer cells. Tumour Biol 39:1010428317706918

92. Goc J, Germain C, Vo-Bourgais TK, Lupo A, Klein C, Knockaert $\mathrm{S}$, de Chaisemartin L, Ouakrim H, Becht E, Alifano M, Validire P, Remark R, Hammond SA, Cremer I, Damotte D, Fridman WH, Sautes-Fridman C, Dieu-Nosjean MC (2014) Dendritic cells in tumor-associated tertiary lymphoid structures signal a Th1 cytotoxic immune contexture and license the positive prognostic value of infiltrating CD8+ T cells. Cancer Res 74:705-715 
93. Weinstein AM, Giraldo NA, Petitprez F, Julie C, Lacroix L, Peschaud F, Emile JF, Marisa L, Fridman WH, Storkus WJ, Sautes-Fridman C (2019) Association of IL-36gamma with tertiary lymphoid structures and inflammatory immune infiltrates in human colorectal cancer. Cancer Immunol Immunother 68:109-120

94. Weinstein AM, Chen L, Brzana EA, Patil PR, Taylor JL, Fabian KL, Wallace CT, Jones SD, Watkins SC, Lu B, Stroncek DF, Denning TL, Fu YX, Cohen PA, Storkus WJ (2017) Tbet and IL-36gamma cooperate in therapeutic DC-mediated promotion of ectopic lymphoid organogenesis in the tumor microenvironment. Oncoimmunology. 6:e1322238

95. Mao D, Hu C, Zhang J, Feng C, Zhang Z, Wang J, Man Z, Zhu Z, Wang Y, Zhao H, Zhu X, Ouyang J, Dong X, Zhao X (2019) Long noncoding RNA GM16343 promotes IL-36beta to regulate tumor microenvironment by CD8(+)T cells. Technol Cancer Res Treat 18:1533033819883633

96. Chen Y, Sun J, Huang Y, Liu Y, Liang L, Yang D, Lu B, Li S (2019) Targeted codelivery of doxorubicin and IL-36gamma expression plasmid for an optimal chemo-gene combination therapy against cancer lung metastasis. Nanomedicine 15:129-141

97. Hewitt SL, Bai A, Bailey D, Ichikawa K, Zielinski J, Karp R, Apte A, Arnold K, Zacharek SJ, Iliou MS, Bhatt K, Garnaas M, Musenge F, Davis A, Khatwani N, Su SV, MacLean G, Farlow SJ, Burke K, Frederick JP (2019) Durable anticancer immunity from intratumoral administration of IL-23, IL-36gamma, and OX40L mRNAs. Sci Transl Med 11(477):eaat9143. https://doi. org/10.1126/scitranslmed.aat9143

98. Takada K, Okamoto T, Tominaga M, Teraishi K, Akamine T, Takamori S, Katsura M, Toyokawa G, Shoji F, Okamoto M, Oda Y, Hoshino T, Maehara Y (2017) Clinical implications of the novel cytokine IL-38 expressed in lung adenocarcinoma: possible association with PD-L1 expression. PLoS ONE 12:e0181598
99. Qu Q, Zhai Z, Xu J, Li S, Chen C, Lu B (2020) IL36 cooperates with anti-CTLA-4 mAbs to facilitate antitumor immune responses. Front Immunol 11:634

100. Ridker PM, MacFadyen JG, Thuren T, Everett BM, Libby P, Glynn RJ, Group CT (2017) Effect of interleukin-1beta inhibition with canakinumab on incident lung cancer in patients with atherosclerosis: exploratory results from a randomised, doubleblind, placebo-controlled trial. Lancet 390:1833-1842

101. Lust JA, Lacy MQ, Zeldenrust SR, Dispenzieri A, Gertz MA, Witzig TE, Kumar S, Hayman SR, Russell SJ, Buadi FK, Geyer SM, Campbell ME, Kyle RA, Rajkumar SV, Greipp PR, Kline MP, Xiong Y, Moon-Tasson LL, Donovan KA (2009) Induction of a chronic disease state in patients with smoldering or indolent multiple myeloma by targeting interleukin 1 \{beta\}-induced interleukin 6 production and the myeloma proliferative component. Mayo Clin Proc 84:114-122

102. Baker KJ, Houston A, Brint E (2019) IL-1 family members in cancer; two sides to every story. Front Immunol 10:1197

103. Murrieta-Coxca JM, Gutiérrez-Samudio RN, El-Shorafa HM, Groten T, Rodríguez-Martínez S, Cancino-Diaz ME, CancinoDiaz JC, Favaro RR, Markert UR, Morales-Prieto DM (2020) Role of IL-36 cytokines in the regulation of angiogenesis potential of trophoblast cells. Int J Mol Sci 22(1):285

104. Bridgewood C, Fearnley GW, Berekmeri A, Laws P, Macleod T, Ponnambalam S, Stacey M, Graham A, Wittmann M (2018) IL-36gamma Is a strong inducer of IL-23 in psoriatic cells and activates angiogenesis. Front Immunol 9:200

Publisher's Note Springer Nature remains neutral with regard to jurisdictional claims in published maps and institutional affiliations. 